Conclusions. Determination of risk factors of endothelial dysfunction, in particular, polymorphism of genes of folate metabolism, gene of endothelial synthase nitric oxide and homocysteine when planning pregnancy or in early gestation allows to assess the course of BA and the presence of possible complications of pregnancy and the health of the newborn

\title{
Reference
}

1. Babtseva A.F., Prikhodko O.B., Romantsova E.B., Landishev Y.sfunction S., Kostrova I.V.. Dynamics of mild persistent bronchial asthma course in pregnant women. Breath physiology and pathology Journal, 2012. 46. P.39-43.

2. Voronina L.P. Clinical-diagnostic and prognostic value of the study of endothelial dysfunction and myocardial remodeling in bronchial asthma/ abstract of thesis...doctor of medical sciences. Astrahan', 2012. 48 p.

3. Lavrova O.V., Dymarskaya Y.R. Bronchial asthma and pregnancy. Practical pulmonology. 2015. 4. P. 2-9.

4. Luchnikova T.A., Prikhodko O.B. Features of social-economic status in pregnant women with bronchial asthma. Breath physiology and pathology Journal, Blagoveshchensk, 2015. Issue 56. P.78-82.

5. Prikhodko O.B. Clinical and functional features of bronchial and lung systems and neuro-vegetative regulation in patient with asthma in during pregnancy and their effects on offspring. abstract of thesis...doctor of medical sciences. Blagoveshchensk, 2010. 44 p.

6. Prikhodko O.B. Neurovegetative regulation and hemodynamics of pregnant women with bronchial asthma // Allergology and Immunology Journal. 2009. V. 10, № 1. P. 84.

7. Prikhodko O.B., Babtseva A.F., Romantsova E.B. Influence of clinical and functional features of bronchopulmonary system at pregnant women with asthma on the condition of child. International journal on immunorehabilitation. 2010 . N. 12 . № 2. c.114a.

8. Prikhodko O.B., Babtseva A.F., Romantsova E.B. The role of controlled asthma in the development of complications in pregnancy and impact on the health of newborns. International journal on immunorehabilitation. 2009. T.11, №1. C.38-39.

9. $\quad$ Prikhodko O.B., Babtseva A.F., Romantsova E.B., Landyshev Y.S., Luchnikova T.A., Smorodina E.I., Kostrova I.V. The lack of asthma control during pregnancy as a predictor of perinatal complications. Allergology and Immunology Journal. 2013. V. 14. № 3. P.188-189.

10. Romantsova E.B., Babtseva A.F., Prikhodko O.B.. Medical and social status of pregnant women with asthma. International journal on immunorehabilitation. 2009. P.38a.

11. Luchnikova T.A., Prikhodko O.B., Babtseva A.F., Romantsova E.B., Pogrebnaya M.V., Smorodina. Evolution clinical and epidemiological course of bronchial asthma in during pregnancy. The 11th Sino-Russia forum of biomedical and pharmaceutical science: the conference proceedings. Harbin, 2014. P.166-167.

\section{UDC 174 DOI 10.22448/AMJ.2017.3.138-139 \\ ETHICS AND DEONTOLOGY IN THE PHYSICAL CULTURE AND SPORTS AMONG MEDICAL STUDENTS}

\section{F.S. Mironov, V.V. Moseikina}

Amur State Medical University Blagovescshensk, Russia

Keywords: ethical norms, deontology, the relationship between the teacher and the student, the professional activity of the doctor.

Abstract: The article is devoted to the question of the correct ethical education of medical students and to the relevance of their involvement in regular physical activity.

Maintenance of the physical form is the important condition for doctor's effective activity, the guarantee of endurance, the possibility to overcome overloads, stress, moreover, it is the factor of professional longevity.

The certain ethical norms and rules of conduct exist at any specialty. Deontology among medical students in sports includes issues, which are relating the relationship between the athlete and the coach, as well as the relationship of students among themselves and with rivals. All these aspects will play a role in shaping of the type of communication between the doctor and the patient in future.

Different kinds of sports elaborate the habit to play in a team, when everyone learns to win together with other members of team, that is, they work for a common result. Teamwork - the ability to understand team members without words, to support the game initiative, to enjoy the success of everyone, to experience mistakes together, to give each other the belief in victory, is achieved in sports. These skills are necessary for doctor's communicating with colleagues and patients. The involvement of future doctors in sports disciplines, helps form "fighting" qualities: to fight till victory, to respond to defeat adequately. It is actual, that the experience of sport struggle forms respect for the law, what is important for the development of professional ethics. After all, in sports, as in medicine, where everyone is in sight, we have to subdue emothions, and to "play" only according to the rules.

In sport, the struggle goes on until the last moment, in medical practice the struggle for human life goes the same way. Therefore, in sport and medicine, the time and energy of man is valued as nowhere. Moreover, it is an essential aspect for a medical student that in sport decisions are made instantly, it helps to worked out the speed of reaction and endurance. The balance of competition - cooperation is necessary for students of medical schools. This balance is formed by: greeting the opponent before the start of the com- 
petition and at it's end, strict adherence to the draw, respect for the judges and a number of other rules.

As for the relationship between the teacher and the student, the first task of the teacher should be taking care of health, safety and well-being of the student. The teacher is obliged to promote accustoming future doctors with the help of acquired sport experience to regular physical activity for health strengthening, what will be a good example for patients.

In addition, deontological principles also determine certain requirements for the appearance of sportsman. Sportswear must correspond to the requirements, which is set by the specific of classes and by the rules of competitions in various sports. It is necessary to use replaceable shoes. The hair should be carefully braided, nails should be short-cropped. It is very important to use perfume cautious and moderately because some students can be intolerant of various substances, which can cause different reaction: hives, asthma attack and other impairments.

These deontological principles help to develope among students the right habits in terms of hygiene and sanitation.

In conclusion, it should be noted that such discipline as physical culture plays an irreplaceable role in the formation of ethically and deontologically correct standards, it can be an excellent foundation for the emergence of literate specialists in any branch of medicine.

\section{UDC 616-092.9 DOI 10.22448/AMJ.2017.3.139-140 EFFICIENCY OF THE USE OF DIGIDROQUERCETIN IN GENERAL COOLING OF THE ORGANISM OF OLD RATS}

\section{Namakonova V.S.}

\section{Amur State Medical Academy, Blagoveshchensk, Russian Federation}

Abstract. An analysis of the data obtained showed that the effect of low temperature on the organism of old rats leads to a significant decrease in the regenerative potential of the airway epithelium and the activation of lipid peroxidation (LPO) reactions in lung tissue and peripheral blood. The use of dihydroquercetin (DKV) on the background of cooling normalizes the reactions of LPO, activates proliferative processes in the epithelium of the respiratory system.

Key words: airway epithelium, low temperatures, reactions of lipid peroxidation, dihydroquercetin.

Itisknownthatlowambienttemperatureshavea negativeimpactontherespiratorysystem, whilethelevelsofLPOproducts increase reliably. Excess formation of these products can cause damage and death of cells. The reaction of cells and tissues to low temperatures depends on the age of the organism, because as the aging process, the level of metabolic processes decreases, which leads to excessive accumulation of LPO products and activation of oxidative stress [2]. In this connection, the study of a natural preparation of dihydroquercetin (DKV), which has a high antioxidant activity, is of special interest.

Materials and methods The work was performed on non-native white rats in the amount of 70, at the age of 19-20 months (old). The experimental animals were divided into groups: 1 . Intact; 2 . Animals that were subjected to general cooling for 14 days for 3 hours daily at a temperature of $-15^{\circ} \mathrm{C}$. 3. The animals of this group were orally injected with DHQ at a dose of 5 $\mathrm{mg} / 100 \mathrm{~g}$ for 2 weeks, then these rats were cooled for 14 days 3 hours daily at $-15^{\circ} \mathrm{C}$, continuing oral administration of DKB.

The object of the study was the cranial and caudal sections of the mucous membrane of the trachea, as well as the wall of the lobar and intralobular bronchi. For the study, pieces of tissue were cut from the appropriate sections. Half-thin sections were stained with toluidine blue. For a general morphological study, the preparations were stained with hematoxylin and eosin. Photographing was carried out on a microscope "Primo Star" Germany. Biochemical examination was performed on lung tissue and peripheral blood. To determine the products of lipid peroxidation and vitamin E, lipids from lung tissues were extracted by the Blay-Dyer method (1975). In the extract, diene conjugates, lipid hydroperoxides, malonic dialdehyde, vitamin $\mathrm{E}$ and ceruloplasmin were determined.

Results and discussion The internal lining of the mucous membrane of the proximal parts of the respiratory tract is represented by a multi-row prismatic ciliated epithelium located on the basal membrane. In old rats ciliated cells are often found in the process of elimination, both without morphological changes, and with signs of partial destruction of the ciliary apparatus and structural rearrangement of the nucleus [2]. With the action of cold from the epithelium, elements on the apical surface of which there are no cilia are often eliminated. There are zones of hypertrophic ciliated cells, as well as degenerate cells "bright cells" with signs of cytoplasm and nucleus dystrophy. The number of basal cells decreases significantly. In the intralobular bronchi, ciliated cells and Clara cells (CK) are present in the epithelium, capable of self-renewing their own population and differentiation into ciliate cells. Vaccination of the cytoplasm in some ciliated cells in old rats, part of the QC loses contact with the basal membrane. With a general cooling in old rats, the number of ciliate cells decreases by almost $20 \%$, many of them have degenerately altered nuclei, a vacuolarized cytoplasm. The effect of low temperatures leads to a significant increase in the level of LPO in the lung tissue; the indicators of diene conjugates are increased by $24.6 \%$, hydroperoxide by $12.4 \%$. The level of vitamin E, responsible for antioxidant protection, decreased by $44 \%$. A similar trend was also observed on the part of the blood indices, the content of diene conjugates increased sharply by $25 \%$, hydropericids by $29 \%$, malonic dialdehyde by $33 \%$, while a decrease in vitamin E by $13 \%$, ceruloplasmin by $17 \%$ was observed.

The use of DKV on the background of the effects of cold leads to a moderate increase in the number of basal cells. The ciliated cells acquire a more typical structure. In the small bronchus the epithelium is predominantly two-rowed, the number 